\title{
Factors impacting Purchase Behaviour of Automobiles Post Covid-19
}

\author{
Sachin Shetty 1 \\ ${ }^{1}$ Symbiosis Institute of Operations Management, Symbiosis International (Deemed University), Pune, India
}

\begin{abstract}
Vehicle Purchase has been rapidly increasing and since last decade the automobile sector has been growing in double digits in India. There are several factors considered by an individual during the purchase of automobile. With the changing trend and with the pandemic situation safety has also been a key factor that adds into it. This paper tries to examine the factors impacting the purchase behaviour. Initially the literature review aims at finding out the significant variables that act as components in purchase of a vehicle. Subsequently, the paper uses statistical technique of Exploratory factor analysis ( EFA ) to club the different variables into single factor. It was found that 21 variables fall into 6 factors namely Brand trust, Socio-demographic factor, Economic factor, Product and tech factor, Psychographic \& safety factor and Govt infra \& policies factor.
\end{abstract}

Keywords:

Covid-19, Consumer Behaviour, Personal Mobility, Used Vehicle, Purchase Behaviour.

Article Received: 10 August 2020, Revised: 25 October 2020, Accepted: 18 November 2020

\section{Introduction}

Towards the end of December 2019, there was something strange that started happening in Wuhan, China. People were falling ill and there began emergence of flu, pneumonia like cases. By the month of Jan 2020, the virus was identified and it's been named as the novel Corona virus of 2019 aka Covid-19. And this dreadful virus started spreading into every nook and corner of the world.

In India too, the number of confirmed cases started rising steeply and steadily. And the govt sprang into action to curtail it. On March 24, India announced the first major lockdown for the next 21 days by then India already had 560 odd confirmed cases. Everything came to a stand-still. The Roads were empty and all of the chaos of daily happenings suddenly turned to silence. Even though the entry \& movement of people were restricted the cases increased steeply.

Fearing the far ill effects of lockdown on the economy, the govt started lifting the lockdown in phase wise with strict social distancing and other norms that were set in place for the citizens to follow.

There was a clear indication from the government that people should learn to start living along side with virus unless there is major breakthrough with vaccination. Everybody was instructed to take care of themselves for the days to follow. With the daily Situation started getting back to old ways with the new normal being that of wearing a mask and maintaining social distance wherever possible was compulsory. With this being in mind people started considering commuting with personal vehicles as a safer choice.

In India not everyone owns a personal vehicle. According to NITI Ayog, India has 22 cars per every 1000 people whereas in countries like USA and UK the numbers are 980 and 850 respectively. Many rely on two wheelers for personal mobility. But two wheelers are generally good for shorter distances. Hence the reliance on public transport is humongous as it is at times convenient \& cheaper to travel.

Looking at the current scenario with Covid-19, this picture is suddenly becoming worrisome. As the Public transport systems are generally over occupied this might lead to a perception of being the breeding ground of corona virus spread.

With Covid-19 effecting every industry adversely and even the minds of the people with the safety of travel in public transport. let us have a perspective whether the pandemic has created any impact on the buying preferences with regard to automobile segment as a whole considering the used vehicle segment as well, as there were imbalances in demand and supply with respect to buying of new vehicles. 


\subsection{Literature Review}

\section{Methodology}

India being one of the most populous country in the world and with the paced economic development in the country, the purchasing power of its citizens has increased considerably due to which motor vehicles like 2 wheelers, 3 wheelers and 4 wheelers are more and more affordable as a large section can afford it \& the Indian market price sensitive. The number of registered vehicles has now risen from 115 million in 2009 to 250 million in 2017. [moRTH,2019]

There are several studies conducted on vehicle buying choices like the author [Shirgaokar (2012)] studied the factors like socioeconomic and demographic factors and others like locations of home, distance of workplace, travel characteristics etc that influenced the families belonging the lower and middle class for opting out a twowheeler or a four-wheeler. This study was based on the Mumbai metropolitan city. The paper hinted that younger crowd had more affinity towards two wheelers and older crowd had more inclination towards four wheelers.

The studies done by [(Potoglou and Kanaroglou, 2008; Nolan, 2010)] pointed out other factors that can impact like the size of the house hold has an impact on purchase decision as more the number of people in the household greater would be the travel needs, Even the salary structure has a positive impact on the purchase behaviour as they can avail loan to purchase the vehicle they need.

Yang et al. (2015) study showed that age of the house hold members play an important factor in deciding the vehicle. The study done by [Srinivasan et al. (2007)] showed that having a child (age less than 18 years) in the family can also play a stimulus for the purchase of vehicle. In the case of elderly member present in the family, they may tend to own a four-wheeler as they would find public transport not convenient as per their needs and Younger adults (age 18 to 35) may tend to own two-wheelers.

The Used vehicle segment was initially not one of the attractive markets for automakers but it was Maruthi Udyog who became the first movers the into the "certified used car segment" since then the firm has grown leaps and bounds. This has not only helped them retain customers using their easy buy back and sell program and also gain new customers. Currently the used vehicle segment is growing at a CAGR of more than $10 \%$. The factors that influenced consumers into purchase of these cars were mainly budget constraints, Desire to own a car, driving skill etc which had a significant influence [Shiva Shankar (2016)]. The above study also stated that consumers preferred to buy from unorganised sectors as the price was negotiable. While the factors like Brand, Resale value, availability of spare parts were not found to be significant

The Effect of corona virus cannot be neglected on the purchase decision of the individuals. Hence on this regard there was a study conducted by [Yan et al. (2020)] which tried to focus on the changes and the factors that influenced individual purchase decision regarding automobiles. Structural equation logit model was used to analyse the results. The factors taken into consideration by the author were age, gender, household income, residential location, vehicle availability, driving licence $\&$ impact of income were considered. The results stated that above factors influenced the consumers in buying the vehicle even though they intend to buy. It also hinted that the outbreak had actually influenced their purchase decisions. This paper was regarding the Chinese population and it was aimed at purchase of new vehicle.

With the wide spread of corona virus, people are finding new ways of Living and working. Work from home has become common. As the disease is an airborne, infectious which would spread easily in places where humans are close and densely packed in public transport like bus, train, metro and planes. Hence there is a fear that has been attached to the use of these transports. And this stigma is likely to last when the social distance measures will be relaxed or removed in the future. Across the European union the public transport is one of those effected modes and has seen strong decrease and people are preferring other mode of choices. People are preferring carpooling as one of the viable option to avoid the public transport [Falchetta, G., \& Noussan, M.,(2020)]

There is no study in the existing literature that discusses the effect of Covid-19 on personal mobility choices and whether people are willing to go ahead with used vehicle in the perceived interest of safety aspect considering the huge gap in demand and supply of new automobiles. The paper [Yan et al. (2020)] which was limited to the view of Chinese citizens. Therefore, it is important to view the impact from the India's point of view. 


\subsection{Research Methodology}

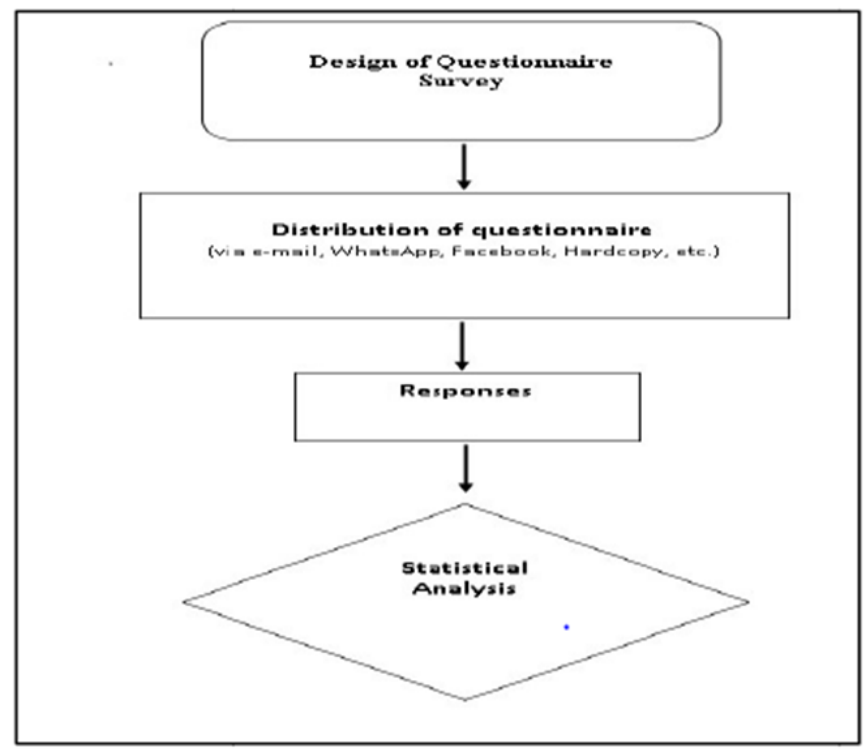

Fig 1. Methodology diagram

The Methodology or the way in which this research paper was carried out was by understanding the factors that affect the purchase decisions through extensive literature review. Then a Survey form was created keeping in mind the above influencing factors. The Survey form was created using Google Forms and sent to Respondents using various social media and digital avenues, Email and distribution of hard Copy forms. The responses were noted and for analysing the data statistical grouping technique called Exploratory Factor Analysis ( EFA) was used to analyse the factors that would impact the purchase. This statistical method was chosen so that big pool of data can be analysed and it can be identified into different factor structures the results are put across in the paper.

\subsection{Data Collection}

Data is collected from August 2020 to September 2020 using a structured questionnaire. The instrument was subdivided into two sections. First section consisted of basic details like name Age, Educational Qualification etc. The second section comprised of the factors that influence in purchase of automobiles. On the 5 point Likert scale, responses ranged from 1 (Strongly disagree) to 5 (strongly agree).

\subsection{Preliminary Analysis}

In the Preliminary Analysis, correlation matrix between various variables are found out. If the correlation value is less than certain threshold value i.e. $(r<0.3)$ it indicates that there very less significant correlation between the variables. Hence these variables would be removed as there is little or no relationship between them and hence, they do not form a cluster. In the Anti Image correlation Matrix all the diagonal elements with value above the threshold value of 0.5 are analysed. In the initial phase in performing Exploratory factor analysis a test known as KMO and Bartlett's test is done. The sample size was 300 and the number of variables were 21 . The KMO value was 0.757 which says that the sample size is enough to perform the analysis.

KMO and Bartlett's Test

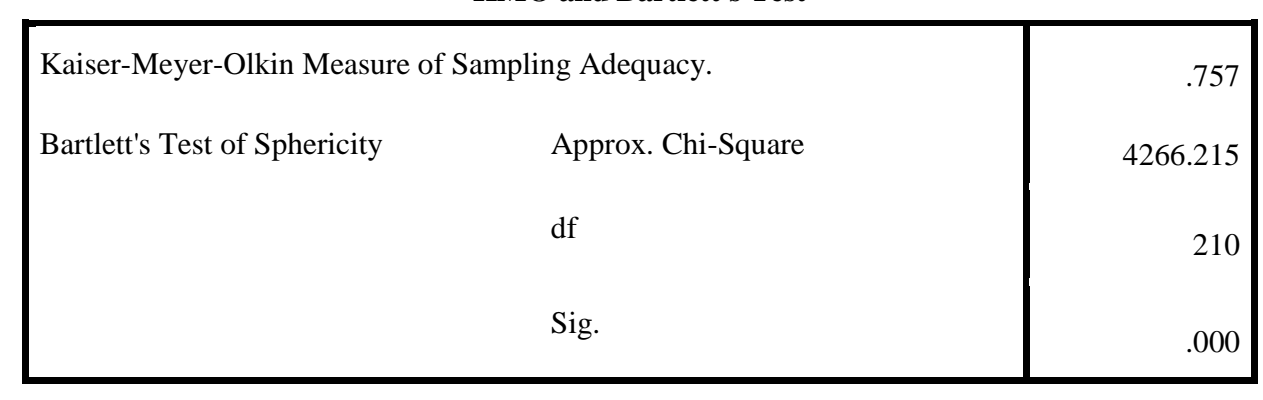

Table 1: KMO Measure of Sampling Adequacy and Bartlett's Test of Sphericity (SPSS Output)

\subsection{Factor Extraction}

Initially during analysis, it is assumed the factors are not correlated to each other. For Extraction of factors, Principal Component Analysis along with varimax rotation was conducted using the SPSS software. There Appeared to be 6 factors with
$24 \%$ of variance. For the values whose Eigen values were more than 1 the extraction sum of square loadings is displayed in table 2.

The percentage variance of the 1 st factor is 24.45 $\%$, the variance of the 2 nd factor is $9.64 \%$, variance of the 3rd factor is $8.65 \%$, 4th factor has 
$8.20 \%$ of variance, 5 th factor has $7.51 \%$ variance and the 6th factor. As the 1st factor has highest variance it explains most variance and the other factors explain lesser variances.

\begin{tabular}{|l|r|r|r|}
\hline \multirow{2}{*}{ Component } & \multicolumn{3}{|c|}{ Initial Eigenvalues } \\
\cline { 2 - 4 } & Total & \% of Variance & Cumulative \% \\
\hline 1 & 5.136 & 24.458 & 24.458 \\
3 & 2.026 & 9.646 & 34.104 \\
4 & 1.820 & 8.665 & 42.769 \\
5 & 1.723 & 8.207 & 50.976 \\
6 & 1.579 & 7.518 & 58.494 \\
7 & 1.108 & 5.277 & 63.771 \\
8 & .930 & 4.429 & 68.200 \\
9 & .863 & 4.110 & 72.310 \\
10 & .800 & 3.810 & 76.120 \\
11 & .753 & 3.588 & 79.708 \\
12 & .723 & 3.443 & 83.150 \\
13 & .711 & 3.384 & 86.535 \\
14 & .539 & 2.569 & 89.103 \\
15 & .517 & 2.462 & 91.566 \\
16 & .468 & 2.229 & 93.795 \\
17 & .410 & 1.951 & 95.746 \\
18 & .335 & 1.594 & 97.340 \\
19 & .285 & 1.357 & 98.697 \\
20 & .258 & 1.227 & 99.924 \\
21 & .014 & .068 & 99.992 \\
\hline
\end{tabular}

Table 2: Variance explained by each component (SPSS Output)

Due to Rotation of factors the percentage variance now with respect to the first factor is $22.73 \%$, 2nd factor variance is $9.91 \%$, 3rd factor variance is $9.18 \%$, 4th factor variance is $8.30 \%$, 5th factor variance is $8.30 \%$ and the 6 th factor explained variance comes up to be $5.32 \%$.

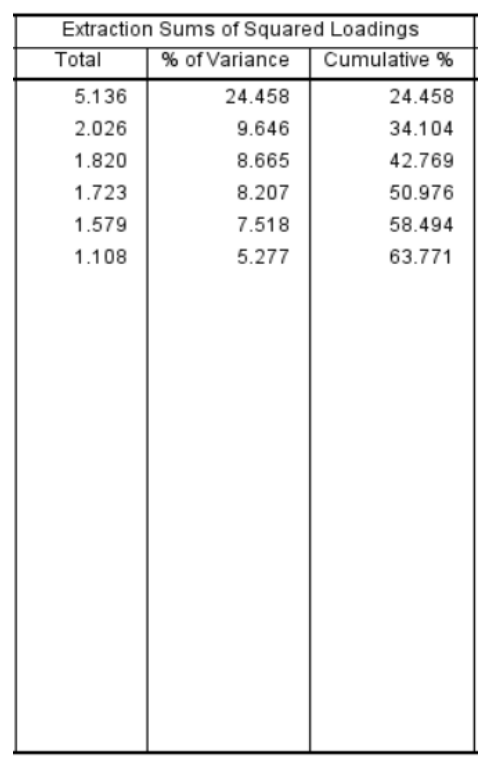

Table 3: Extraction Methodology

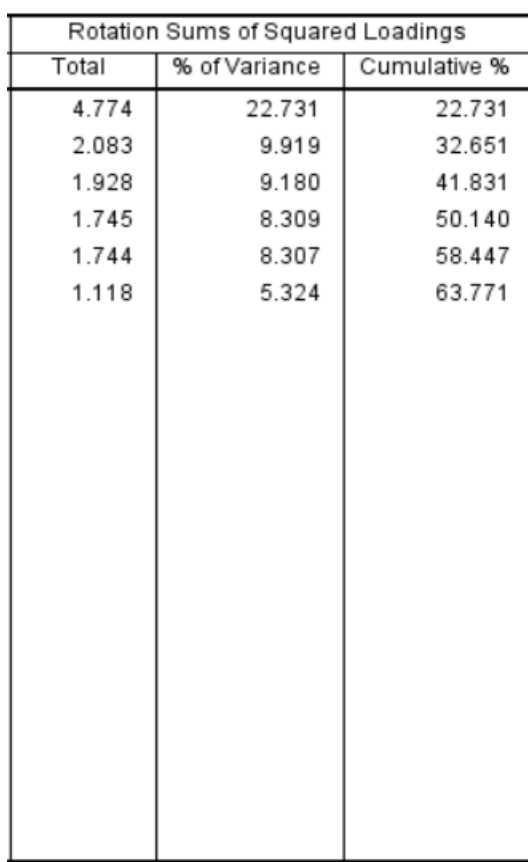

Table 4: Variance Explained after Rotation

Table 5 shows the Communalities, In here the values range from 0.456 to .844 . If any variable has a value less than 0.40 then they are not loaded into any factors and thus not considered while performing the analysis using EFA [Child, 2006]. 2.6 Factor Retention

After the factor extraction the further step is to the retained factors that show higher significance. According to (Kaiser, 1960) one such way is to retain all factors which has a eigen values above 1. Considering this rule, in the analysis there are found to be Six factors that are having Eigen values above 1 and these factors are retained. 
Communalities

\begin{tabular}{|c|c|c|}
\hline & Initial & Extraction \\
\hline Vehicle Specification \&amp; Performance & 1.000 & .842 \\
\hline Loan availability & 1.000 & .577 \\
\hline Aesthetics, Interiors, Exteriors & 1.000 & .844 \\
\hline Opinion of Mechanic, Friend, Family & 1.000 & .840 \\
\hline Dealership Reputation & 1.000 & .443 \\
\hline Not feeling safe in public transport & 1.000 & .841 \\
\hline Govt Policies & 1.000 & .601 \\
\hline presence of old people at home & 1.000 & .690 \\
\hline Employment Status & 1.000 & .502 \\
\hline desire to own a car & 1.000 & .838 \\
\hline Word of mouth & 1.000 & .841 \\
\hline Availability of service centre & 1.000 & .615 \\
\hline presence of child at home & 1.000 & .641 \\
\hline Area of residence - Rural, semi-rural, Urban, Semi urban & 1.000 & .457 \\
\hline Brand Trust, Brand value, Brand Endorsement & 1.000 & .456 \\
\hline Education & 1.000 & .584 \\
\hline Low waiting period & 1.000 & .561 \\
\hline Marital status & 1.000 & .475 \\
\hline Good Public transport & 1.000 & .531 \\
\hline family composition - Nuclear, Joint etc & 1.000 & .619 \\
\hline Budget Constraint \&amp; outstanding Loan & 1.000 & .596 \\
\hline
\end{tabular}

Table 5: Communalities of Variables (SPSS)

Table 5 shows the Communalities, In here the values range from 0.456 to .844 . If any variable has a value less than 0.40 then they are not loaded into any factors and thus not considered while performing the analysis using EFA [Child, 2006].

\subsection{Factor Retention}

After the factor extraction the further step is to the retained factors that show higher significance. According to (Kaiser, 1960) one such way is to retain all factors which has a eigen values above 1. Considering this rule, in the analysis there are found to be Six factors that are having Eigen values above 1 and these factors are retained.

\subsection{Factor rotation \\ Component Matrix \\ Component Matrix ${ }^{\mathrm{a}}$}

\begin{tabular}{|l|l|l|l|l|l|l|}
\hline \multicolumn{1}{|l|}{} & Component & 1 & 2 & 3 & & \\
\hline
\end{tabular}




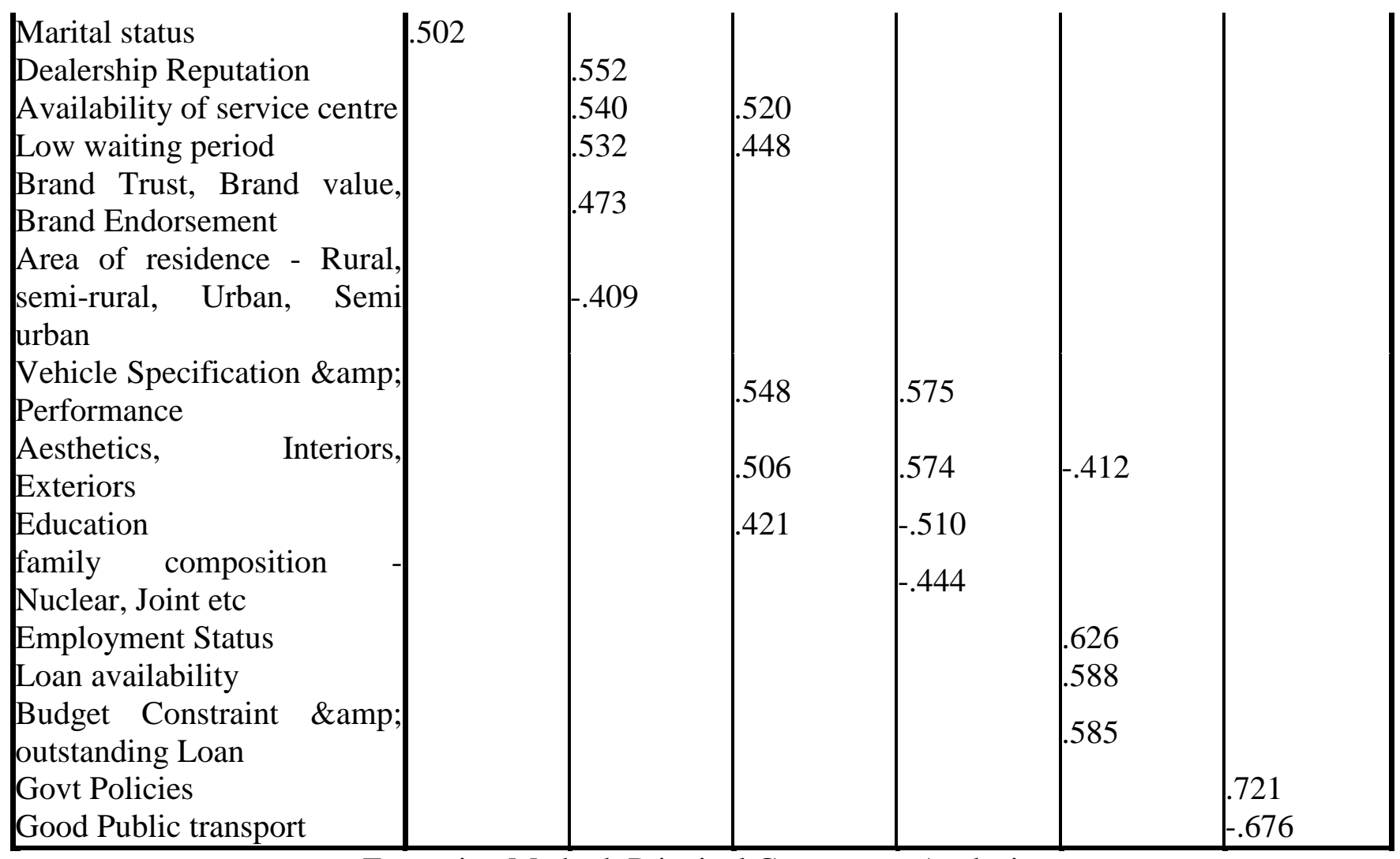

Extraction Method: Principal Component Analysis.

a. 6 components extracted.

Table 6: Extraction Methodology-PCA(Principal Component Analysis)

Rotated Component Matrix ${ }^{a}$

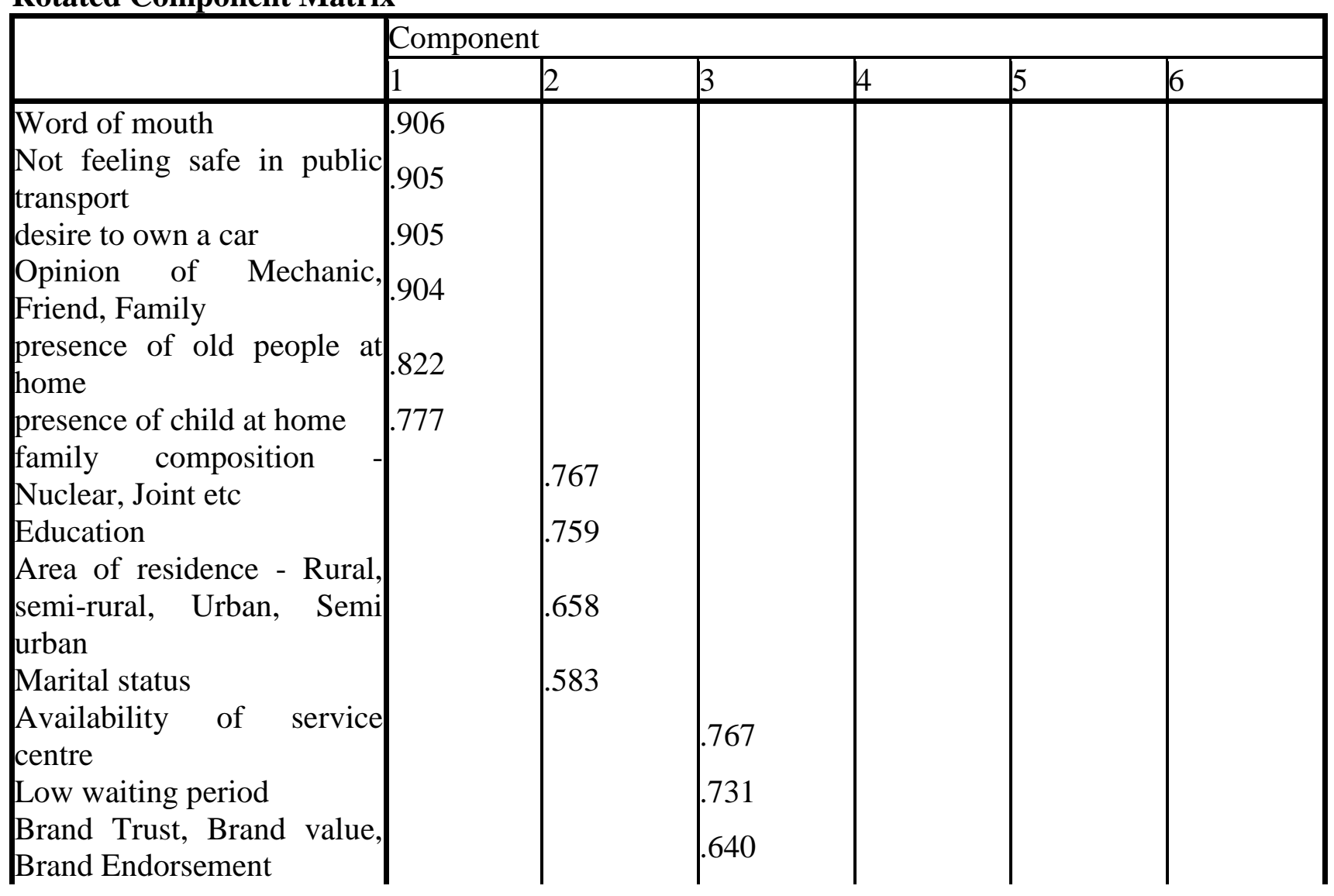




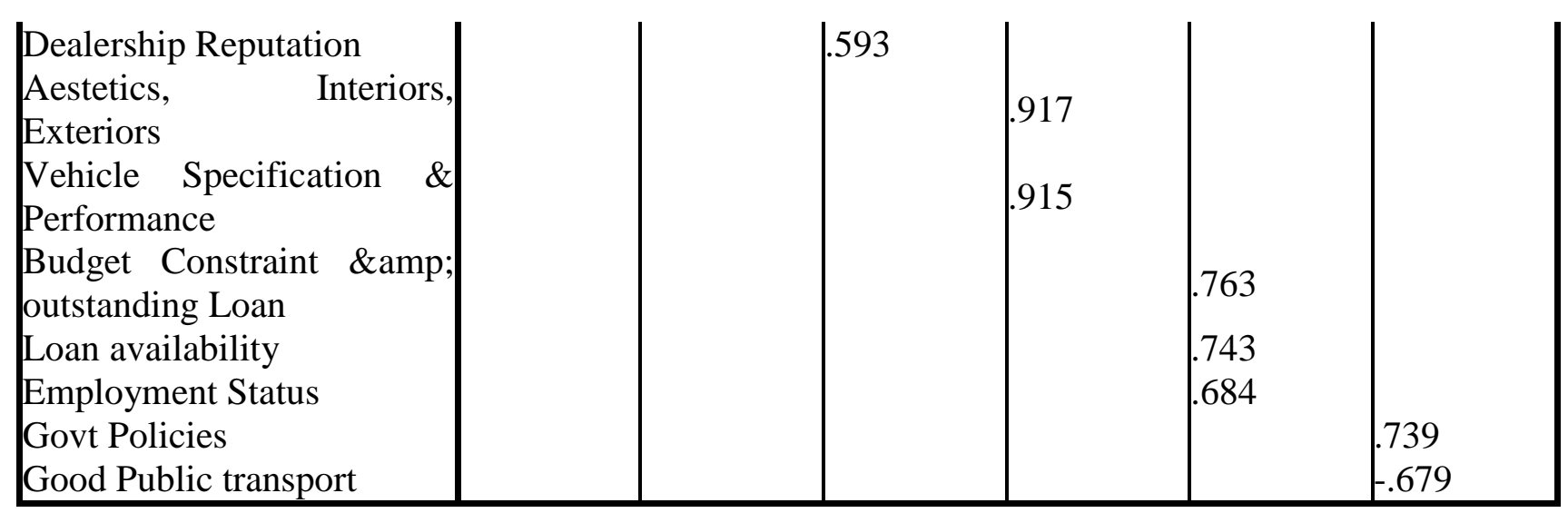

Extraction Method: Principal Component Analysis.

Rotation Method: Varimax with Kaiser Normalization.

a. Rotation converged in 5 iterations.

Table 7: Extraction Methodology-PCA

(Rotation Method: Orthogonal rotation (VARIMAX)

4 Components Extracted

\section{Results}

The Rotated component matrix helps in viewing the results even further:

1st Factor - There are six variables grouped under this factor they are : Word of mouth, Not. feeling safe in Public transport, desire to own a car, Opinion of Mechanic, Friend, Family, presence of old people at home, presence of old people at home these variables are loaded into component 1 with value ranging from 0.777 to .906 . These factors can be named as Psychographic and Safety factor.

2nd Factor - There are four variables grouped under this factor they are : family composition, Education, Area of residence and Marital status and their value ranges from 0.767 to 0.583 . this factor can be labelled as Demographic \& social factor.

3rd Factor - There are again four variables loaded into this factor they are: Service centre availability, Low waiting period, Brand Trust Brand Value and Dealership Reputation and their values ranges from 0.76 to 0.59 and this factor can be together called as Brand Trust Factor.

4th Factor - There are 2 variables loaded into this factor they are: Vehicle Specification \& Performance and Aesthetics and their value ranges from 0.917 to 0.915 and this factor can be named as Product \& Tech Factor

5th Factor - There are 3 variables loaded into this factor and their values ranges from 0.763 to 0.684 and the main variables loaded into this factor are Budget Constraint, Loan availability and
Employment status. Hence this factor can be labelled as Economic factor 6th Factor - there are 2 variables loaded into this factor and their values range from 0.739 to 0.679 . The variables under this factor are Govt policies and Good Public transport. This can be collectively named as Govt policies \& infraFactor.

\section{Limitations}

The Limitations of this study is that it had 21 variables as buying criteria for used vehicles. There can be many more criteria's that can be added and studied. The second limitation is that Majority of the respondents were belonging to Dakshina Kannada district of Karnataka state.

The Sample size for this particular paper was only 300 respondents. Increasing the sample size and the respondents from other parts of the country can be also studied.

\section{Conclusion}

The study done in this paper has major considering factors that go into account while purchase of a personal vehicle. This study will help managers and policy makers to gauge and make their offers attractive in increasing their sales. It would also help them to focus on necessary cluster in order to make their offering much more desirable. And also this can not only help the regular vehicle segment but also the preowned vehicle segment in better giving their value proposition. Digging deep into the factors gives us insights that the government also can reconsider 
their current policies and build better infrastructure in order to catapult the severely affected auto sector back to new heights.

\section{Acknowledgement}

The author wishes to acknowledge Symbiosis Institute of Operation Management for providing the library access to research journals.

Funding: Self-funded

Ethical approval: Not applicable

\section{References}

[1] Yang, J., Kato, H., Ando, R., 2015. Comparative analysis of the household car ownership between Toyota City and Nagoya City. EASTS 11, 626-639.

[2] Falchetta, G. \& Noussan, M. (2020). The Impact of COVID-19 on transport demand, modal choices, and sectoral energy consumption in Europe. IAEE Energy Forum, Special Issue 202

[3] Srinivasan, K., Bhargav, P., Ramadurai, G., Muthuram, V., Srinivasan, S., 2007. Determinants of changes in mobility and travel patterns in developing countries: case study of Chennai, India. Transp. Res. Rec. 2038, 42-52.

[4] Potoglou, D., Kanaroglou, P.S., 2008. Modelling car ownership in urban areas: a case study of Hamilton, Canada. J. Transp. Geogr. 16 (1), 42-54.

[5] Shirgaokar, M., 2012. The Rapid Rise of Middle-Class Vehicle Ownership in Mumbai. University of California, Berkeley Doctoral Dissertation.

[6] MoRTH, 2019. Road Transport Year Book 2018-19. Transport ResearchWing, Ministry of Road Transport \& Highways, Government of India, New Delhi.

[7] Yan, Y., Zhong, S., Tian, J., \& Jia, N. (2020). An Empirical Study on Consumer Automobile Purchase Intentions Influenced by COVID-19. Available at SSRN 3593963.

[8] Tao Qinglin Qi Lihui Wang,AYC Nee Engineering Volume 5,Issue 4,August 2019, Pages 653-661
[9] Tabachnick, B. G., \& Fidell, L. S. (2007). Using multivariate statistics (5th ed.). Boston, MA: Allyn \& Bacon

[10] Costello, A.B., \& Osborne, J.W. (2005). Best practices in exploratory factor analysis: Four recommendations for getting the most from your analysis. Practical Assessment, Research and Evaluation, 10(7), 1-9.

[11] Bartlett, M. S. 1954. A note on the multiplying factors for various $\chi 2$ approximations. Journal of the Royal Statistical Society. Series B (Methodological), 296-298.

[12] Child, D. (2006). The essentials of factor analysis. (3rd ed.). New York, NY: Continuum International Publishing Group.

[13] DeCoster, J. (1998). Overview of factor analysis. Retrieved March 22, 2012 from http://www.stat-help .com/notes.html

[14] Kaiser, H. F. (1960). The application of electronic computers to factor analysis. Educational and Psychological Measurement, 20, 141-151. doi:10.1177/001316446002000116

[15] Cattell, R.B. (1978). The scientific use of factor analysis in behavioral and life sciences. New York, NY: Plenum Press.

[16] Field, A. 2013. Discovering statistics using IBM SPSS statistics, sage.

Software-Statistical Analysis

1.IBM Corp.Releases 2015.IBM Statistics for Windows, Version 23.0. Armonk,NY:IBM Corp. 